\title{
Impact of pre-lab learning activities, a post-lab written report, and content reduction on evolution-based learning in an undergraduate plant biodiversity lab
}

John M Basey ${ }^{1 *}$, Anastasia P Maines ${ }^{1}$, Clinton D Francis ${ }^{2}$, Brett Melbourne1, Sarah B Wise ${ }^{1}$, Rebecca J Safran ${ }^{1}$ and Pieter TJ Johnson ${ }^{1}$

\begin{abstract}
Background: Commonplace biodiversity labs in introductory undergraduate biology typically emphasize declarative knowledge. We contend that shifting these labs to emphasize evolution, higher-order cognition, and science reasoning would benefit student learning. Four factors that likely make evolution-based higher-order learning goals difficult to achieve in these labs are: the novelty and quantity of required declarative knowledge, the number of integrated concepts, the theoretical nature of evolution, and limitations on working memory. Thus, we propose that a model to shift learning from lower-order declarative knowledge to evolution-based higher-order integration in these labs would reduce overall lower-order content, increase time efficiency through hands-on pre-lab activities, and increase evidence-based reasoning through written post-labs that emphasize evolution-based higher-order integration. We tested this contention by comparing exam performances of students who did and did not participate in the redesigned lab.

Methods: A new plant biodiversity lab design was implemented in an introductory undergraduate biology lab class. The lab class was a separate class from the complementary lecture class, but the content-oriented learning goals were similar between the lecture and lab. We compared achievement of students in lecture + lab to those in lecture only with a pre-assessment and a mid-semester exam which contained questions that were both related and unrelated to the plant biodiversity lab learning goals.
\end{abstract}

Results: Students in 'lecture + lab' relative to 'lecture only' did not perform significantly different on the pre-assessment lower or higher-order questions. On the post-assessment, students in lab + lecture performed significantly better on knowledge questions that were unrelated to lab with an improvement of 5.9\%. Moreover, students in lab + lecture also performed significantly better on lab-related knowledge questions and lab-related evolution-based integrative reasoning questions with a range of 6.3 to $11 \%$ improvement, compared to students in the lecture only group.

Conclusions: The proposed framework was successful in improving student learning for both lower-order declarative knowledge questions and evolution-based questions involving higher-order integration of concepts. In addition, because students in lecture + lab outperformed students in lecture only on questions unrelated to lab content, our proposed model highlights the importance of multiple inquiry-oriented lab experiences in higher education.

Keywords: Science education; Biodiversity; Labs; Evolution; Science reasoning

\footnotetext{
* Correspondence: john.basey@colorado.edu

${ }^{1}$ Department of Ecology and Evolutionary Biology, University of Colorado at Boulder, 334 UCB, Boulder, CO 80309-0334, USA

Full list of author information is available at the end of the article
} 


\section{Background}

In undergraduate biology classes, evolution is a key overarching theme that has been documented as a very difficult subject for students to learn (Alters and Nelson 2002, Hokayem and Boujaoude 2008, Timmerman et al. 2008), and science education specialists advocate that it should be taught with an inquiry-oriented approach (American Association for the Advancement of Science 2010). Evolution should be incorporated in all aspects of biology education; it can be divided into two major components: mechanisms of evolution and products of evolution. Almost all introductory undergraduate biology experiences include hands-on laboratory sections (henceforth "labs") as potential avenues for inquiry learning and to help students with science reasoning skills. Biology-lab-education literature has described numerous inquiry-oriented experiences involving experimental, hypothesis-testing to address mechanisms of evolution that can be accomplished in single lab periods using simulations or over the course of several weeks (National Research Council 1998, Kalinowski et al. 2006, Spiro and Knisely 2008, Heil et al. 2012). However, biologylab-education associated with products of evolution, especially biodiversity, is less investigative, more guided and most commonly seen as a "march through the phyla" of living organisms, emphasizing memorizing and characterizing often without much evolution-based integration and with almost no opportunities for evidence-based science reasoning (see Harris-Haller 2008, Vodopich and Moore 2008, Addy and Longair 2009, Scully and Fisher 2009).

Research examining learning in biodiversity labs is rare. According to Smith and Cheruvelil (2009), an attempt to transform biodiversity labs in introductory college biology to investigative labs resulted in a substantial loss in biodiversity content that had to be reconfigured and put back into the curriculum. To make biodiversity labs more inquiry oriented, Timmerman et al. (2008) removed the observational, hands-on components and had students use primary literature to evaluate a research question of their choice. They used a pre/post multiplechoice assessment featuring lower-order-cognition items (i.e. knowledge and comprehension). Although they found a significant improvement from the pre to post assessment: the effect sizes for their inquiry-oriented biodiversity segment in lab + lecture (0.6) were substantially lower than the effect sizes for common-place non-biodiversity segments (plant anatomy $=2.1$, animal anatomy $=1.8$ ), possibly accounted for by differences in time on task and level of abstractness. However, a major gap in this study was that higher-order cognition learning (i.e. application, analysis and synthesis), that would be predicted to benefit from their inquiry approach was only assessed with a student survey. Thus, an important remaining question is:
Can undergraduate biodiversity labs be designed so that they retain their hands-on nature and improve not only students' associated lower-order declarative knowledge, but also their evolution-based higher-order integration of concepts and evidence-based science reasoning?

Why do commonplace undergraduate labs utilize a "march through the phyla" format without much of an emphasis on evolution-based integration of concepts and evidence-based science reasoning? We contend that one possible explanatory model consists of four interacting factors: the novelty and quantity of required declarative knowledge, the high number of integrated concepts, the theoretical nature of evolution, and limitations on working memory.

For example, one evolutionary theme that requires integrated reasoning related to an introductory plant biodiversity lab is: Life originated in aquatic environments and radiated to terrestrial habitats (i.e. water to land). In a "march through the phyla" lab on plant biodiversity, students are guided through observations of characteristics of representative divisions of plants that can relate to the water to land hypothesis (Table 1). Background declarative knowledge required includes a basic understanding of mitosis vs. meiosis, analogous vs. homologous and natural selection. All three concepts are typically thoroughly covered in the preceding classes. Novel associated terminology includes haploid, diploid, gametophyte, sporophyte, vascular tissue, rhizoids, gametes, spores and pollen as well as multiple phylum/division names (e.g. Bryophyta, Hepatophyta, Pterophyta, Lycophyta, Ginkophyta, Coniferophyta, Anthophyta, etc.). Typical "marches through the phyla" end at this stage emphasizing natural history characteristics of each phylum and a mastery of declarative knowledge.

To add an evolution-based integrated component, a teacher could have students utilize their observations and declarative knowledge as evidence supporting or not supporting the water to land hypothesis. Integrated pieces of the argument include, but are not limited to those listed in Table 2. Thus, for students to first obtain the declarative knowledge and follow it by constructing their evolutionbased integrated reasoning, they place a high demand on their working memory (i.e. the location in the brain where processing of information occurs).

At the intersection between cognitive psychology and science education is a theoretical overlay designed to help guide instructional practice that originates from the concept of Miller (1956) that working memory is limited. Within the field of science education the information-processing model was coined the working memory overload hypothesis (see Reid 2008) and from cognitive psychology, the information-processing model originally came from multi-media instruction and is called cognitive load theory (see van Merrienboer and 
Table 1 Observational data students gather during a plant biodiversity lab that can be related to water to land hypothesis

\begin{tabular}{llllll}
\hline Category & Alternation of generations & Vascular & Dominant generation & Mobility of male gamete & Mobile stage \\
\hline Mosses & + & - & Gametophyte & Water- limited & Spore \\
Ferns & + & + & Sporophyte & Water- limited & Spore \\
Conifers & + & + & Sporophyte & $\begin{array}{l}\text { Dispersed by wind } \\
\text { and some animals }\end{array}$ & $\begin{array}{l}\text { Gametophyte (pollen) and } \\
\text { developing sporophyte (seed) }\end{array}$ \\
Flowering plants & + & & & Sispersed by animals & $\begin{array}{l}\text { Gametophyte (pollen) and } \\
\text { developing sporophyte (seed) }\end{array}$ \\
& & & & & and some wind
\end{tabular}

Sweller, 2005). Both models stem from the basic premise that working memory is limited and can become overloaded when processing involves too many items simultaneously or is too difficult. When working memory is overloaded, schema formation is hampered and the result is simple and fragmented schemas that may not last in long-term memory (i.e. little to no meaningful learning occurs). Thus, unless partial, thoughtful content reduction is pursued in curriculum design, a teacher may be better off having students at least learn some declarative knowledge rather than be overwhelmed.

The fourth component relates to the intellectual development of college students. According to developmental theory, science concepts can be divided into two general categories: descriptive and theoretical with evolution categorized as theoretical (Lawson et al. 1989, Lawson et al. 2000). Descriptive concepts are directly perceptible and testable with easily perceived causal agents and they develop through exposure and experience. Since they do not require extensive intellectual development, they can progress in childhood. Theoretical concepts are not directly perceptible, they can only be indirectly tested and have no perceived causal agent. They require intellectual development based on a foundation of descriptive concepts and they develop later in life in adolescence and early adulthood. Thus, when students are exposed to novel concepts, they require the development of a descriptive understanding before attaining a theoretical understanding (see Lawson et al. 2000).

By combining the quantity of novel declarative knowledge in an introductory plant biodiversity lab, with the multiple components involved for integrative reasoning, with the theoretical nature of evolution and required formal reasoning, and finally a limit to the working memory capacity of students, it may be difficult for students to achieve higher-order integrative learning on this topic. Under these conditions we contend that to achieve evolution-based higher-order integrative learning, a reform curriculum must reduce the overall lower-order declarative knowledge and/or increase time relative to the commonplace lab.

With these ideas in mind, we redesigned the undergraduate plant biodiversity lab in introductory biology to address the following hypothesis.

$A$ biodiversity lab with a hands-on design and a smaller proportional emphasis on lower-order declarative knowledge can still improve students' lower-order declarative knowledge while enhancing their evolution-based, higherorder integration of concepts and evidence-based science reasoning.

To implement this design, we added three-weeks of hands-on pre-lab learning activities that occupied a small portion of the three labs preceding the plant biodiversity lab and focused on lower-order declarative knowledge

Table 2 Five conceptual learning goals that can be integrated with observations from Table 1 for evidence-based argumentation associated with the water to land hypothesis

\begin{tabular}{|c|c|}
\hline Number & Description of learning objective \\
\hline 1 & $\begin{array}{l}\text { The four stages of alternation of generations (i.e. a haploid spore gives rise to a haploid gametophyte, that gives rise to haploid } \\
\text { gametes, that get together and produce a diploid sporophyte, that gives rise to haploid spores) are found in all land plants and } \\
\text { although they may be different in form, they are homologous. }\end{array}$ \\
\hline 2 & The time frame for the water to land hypothesis is in hundreds of millions of years. \\
\hline 3 & $\begin{array}{l}\text { Organisms are limited by resources especially energy. Energetic trade-offs exist between different strategies. An example is } \\
\text { animal-mediated versus wind mediated dispersal and pollination. }\end{array}$ \\
\hline 4 & $\begin{array}{l}\text { The environment is variable in relation to water availability. Adaptations for drier habitats provide an advantage in drier habitats, } \\
\text { but not necessarily for wet habitats because there are associated costs and benefits to the adaptations. }\end{array}$ \\
\hline 5 & $\begin{array}{l}\text { Genetic diversity improves long-term reproductive success. Sexual reproduction is more costly than asexual reproduction, but it } \\
\text { increases genetic diversity. Dispersal and outbreeding are two mechanisms that help increase genetic diversity. }\end{array}$ \\
\hline
\end{tabular}


associated with plant life cycles (i.e. learning goal \#1 in Table 2). We removed phyla/divisions that did not directly pertain to the learning goals. We focused students on the evolution-based higher-order integration of concepts with a post-lab written report that incorporated integration and evidence-based science reasoning. In addition, integration items $2-5$ in Table 2 were addressed to various extents in prior labs. It is also notable that literature on biodiversity education suggests that the use and understanding of phylogenetic trees is important for teaching evolution, a concept coined "tree-thinking" (Smith and Cheruvelil 2009, Meisel 2010). Therefore, tree-thinking was emphasized in several labs prior to the redesigned plant biodiversity lab.

\section{Methods}

\section{Experimental and curricular design}

The study was conducted at the University of Colorado at Boulder in spring 2011 during the general biology lab (GBLII), the second of a two-semester sequence. GBLII is a stand-alone, 1-credit-hour lab class that runs concurrently with a 3-credit-hour lecture class addressing similar content. Approximately $65 \%$ of students in lecture were concurrently taking the lab and $75 \%$ of students in lab were concurrently taking the lecture. GBLII enrolled 864 students that were mostly freshman $(60 \%)$ and sophomores (30\%) with fewer juniors (5\%) and seniors (5\%). Each lab section had up to 18 students and was instructed by a graduate-student teaching assistant (TAs $=24)$.

Most students take both semesters in the sequence. In General Biology Lab I, students participate in a series of inquiry-oriented experimental labs that culminate in an open-ended, research-based, final student-project. GBLII is comprised of a mix of experimental and nonexperimental labs.

The redesigned plant biodiversity lab experience began in the second week of GBLII and ran for 4 weeks. The pre-lab learning activities occupied approximately $30 \mathrm{~min}$ per week for the first three weeks. During the pre-lab learning activities, students observed the stages in the life cycle of the C-Fern (Ceratopteris richardii). They started by pipetting $\mathrm{C}$-fern spores on a growth medium and microscopically observed them. In the following two weeks, students observed the germinating spores and the resulting gametophytes with microscopes, then added water to see swimming sperm and observed fertilization. On the following week students completed a 3-hour lab. In the beginning of the lab, students completed their hands-on investigation of the C-fern and utilized their pre-lab observations to derive a fern life cycle. Students then used observations of living specimens, preserved specimens and microscope slides to compare and contrast the life cycles of mosses, conifers and flowering plants with the fern life cycle. Over the following week, each student produced a document consisting of text, images (hand drawings or digital), and diagrams as evidence to address these two following overarching ideas. 1) Life originated in aquatic environments and then radiated to terrestrial habitats, and 2) Evolution through natural selection with adaptive radiation is an overarching theoretical framework that explains the current diversity of living organisms. To complete the unit, students were given a 20 min practical quiz in lab the following week.

\section{Analysis}

To check for possible entry-level knowledge differences between students in lab + lecture and students in lecture only, we used a pre-assessment given during lecture at the beginning of the spring 2013 semester. This multiplechoice, clicker assessment was implemented in two large lecture classes taught by one professor (267 and 247 students) and one large lecture class taught by another professor (188 students). For this analysis, 7 contentrelated questions used in all three classes were included; questions were categorized as 2 lower-order cognition (knowledge and comprehension), 2 application and 3 analysis level questions (Crowe et al. 2008). Students also indicated whether or not they were taking lab in an additional clicker question.

To assess learning resulting from the newly designed plant-biodiversity lab module, we inserted questions associated with the evolutionary learning goals into the multiple-choice lecture exam that was given 6 weeks after the plant biodiversity lab module. Ten multiplechoice exam questions related to plant biodiversity were written by JMB at the knowledge, comprehension, application and analysis levels of Bloom's taxonomy according to Crowe et al. (2008). The lecture professor (who did not have direct knowledge of the lab contents) chose 5 of these exam questions from each level of learning to include on the lecture exam. In addition, several other exam questions written by the lecture professor that pertained to lab learning goals were also included. At the end, the assessment was comprised of 10 knowledge, 6 comprehension, 6 application and 5 analysis questions. Table 3 provides example questions from the quiz at each level of learning.

Prior to the analysis of the lecture exam, JMB further identified questions on the exam that did not relate to the lab content nor had any terminology in the question that was covered in the lab. Since JMB facilitated and observed in most of the GTAs classes, no "expert" independent reviewers were available. So JMB very conservatively identified these questions. These questions are hereafter described as "unrelated" questions. Only 8 exam questions were identified as unrelated questions in total, all of which were at the knowledge (7) and comprehension (1) levels of learning. Of the 8 questions, 5 dealt with plant 
Table 3 Examples of multiple choice exam questions at each level of learning that associate with learning goals listed in Table 2

\section{Lower-order}

\section{(a) Knowledge}

Which of the following is not correct concerning the generalized life cycle of a plant?

$$
\begin{aligned}
& \text { a. A diploid sporophyte gives rise to a haploid spore through } \\
& \text { meiosis. } \\
& \text { b. A haploid gametophyte gives rise to a haploid gamete } \\
& \text { through mitosis. } \\
& \text { c. Two haploid gametes fuse to produce a diploid zygote. } \\
& \text { d. A haploid spore gives rise to a diploid sporophyte through } \\
& \text { mitosis. } \\
& \text { e. All of the above are correct. }
\end{aligned}
$$

\section{(b) Comprehension}

In seed plants, the pollen grain is an adaptation to overcome the limitations of water for fertilization. Pollen is a modified version of what structure found in seedless plants?
a. A gametophyte containing archegonia.
b. A gametophyte containing antheridia.
c. A sporophyte with archegonia.
d. A sporophyte with antheridia.
e. Spores

\section{Higher-order}

\section{(c) Application}

Suppose a spore landed in a random environment and a seed landed in the same random environment - which one has a higher probability of successfully developing into a mature plant and why?

a. The spore because it can travel through the air farther than a seed.

b. The spore because it requires less energy to get started.

c. The seed because it has endosperm which is stored food to help grow a root and a shoot.

d. The seed because it can travel farther through the air than a spore.

e. Both have an equal probability of successful development in a random environment.

\section{(d) Analysis}

The table below compares the number of pollinating species associated with different species of flowering plants versus the number of pollen grains per flower in the particular species. Which explanation best explains these data?

$\begin{array}{ll}\text { \# of pollinating species } & \text { Approximate pollen grains per flower } \\ 1 \text { to } 3 & 10,000 \\ 3-8 & 100,000 \\ 8-12 & 800,000\end{array}$

a. As the number of pollinating species increases, the pollinators eat more pollen and thus, the flower must make more pollen to compensate.

b. As the number of pollinating species increases, the number of flowers also increases so the number of pollen grains per flower stays the same.
Table 3 Examples of multiple choice exam questions at each level of learning that associate with learning goals listed in Table 2 (Continued)

c. As the number of pollen grains per flower increases, flowering plants switch to using swimming sperm to fertilize their flowers.

d. As the number of pollinating species increases, the probability of a pollinator going to a flower of a different species also increases, thus there may need to be more pollen made so that it gets to the correct flowers.

e. The pollen in these species of flowering plants is transported via wind rather than pollinators.

growth, 2 dealt with water transport and 1 was a generic question about science in general that stemmed from a lecture activity. There were numerous higher-order exam questions, which were excluded from the analysis because they pertained to content covered in other labs. For the statistical analysis, we lumped all questions unrelated to lab into one category of lower-order cognition. We utilized these questions in two ways. First, we compared scores on unrelated questions of lab + lecture students to lectureonly students. Second, for each student, we subtracted the mean score for the lower-order questions related to lab from the mean score for unrelated questions. All comparisons were made using unpaired two-sample ttests in R (R Core Team 2012).

To validate categorization into Bloom's levels, all preexam and exam questions were independently categorized by two outside experienced reviewers and a quadratic weighted kappa (Cohen 1968) was estimated for each reviewer relative to the independent categorization by JMB that was used in this study. Each question was rated as knowledge $=1$, conceptualization $=2$, application $=3$, or analysis $=4$ by each independent reviewer $(N=42)$. We used a quadratic weighted kappa because a categorization mistake between a lower-order question and a higherorder question has more importance than within each category (see Sim and Wright 2005). After categorization, $\mathrm{JMB}$ and the two reviewers met to discuss discrepancies.

\section{Results}

The categorizations of the pre-exam and exam questions by the two independent reviewers were consistent with the categorizations used in the study. For higher-order versus lower-order categorizations, in only 1 out of 84 questions when both reviewers were combined, was a question categorized as a separate category by a reviewer compared with what was used in the study. For that question after reviewers met to discuss the question, it was unanimously agreed that the question was categorized correctly for the study. The quadratic weighted kappa for independent categorizations in all four Bloom's levels (knowledge, comprehension, application, and analysis) 
indicated that categorization of pre-exam and exam questions were highly reliable as well (Table 4).

An unpaired t-test indicated that scores on the preassessment did not significantly differ between lab + lecture and lecture-only students for any of the Bloom's levels of cognition examined (Table 5, Figure 1). Thus, prior to taking the lab course, we found no obvious differences in performance between the two groups. When it came to the post-assessment (exam) questions, however, an unpaired $t$-test for unequal variances indicated that, on the "unrelated" lower-order cognition exam questions (which did not pertain to any lab content material), students in lecture + lab scored significantly higher than students in lecture only, with a mean difference of $4.3 \%$ (Table 5).

For exam questions associated with content addressed by the plant biodiversity lab, an unpaired t-test for unequal variances demonstrated students in lecture + lab scored significantly higher than students in lecture only, on all the Bloom's levels of cognition examined, with a range from 6.3 to $11.0 \%$ (Table 5, Figure 2).

For the measure of mean lower-order exam scores on questions related to lab minus unrelated questions paired by student, the greater the difference the more the lab activities directly helped students learn. An unpaired ttest for unequal variances indicated a significant greater difference for students in lecture + lab than for students in lecture with a mean of $5.9 \%$ (Table 5, Figure 3).

\section{Discussion}

Commonplace introductory college biodiversity labs in the USA have a tendency to focus on lower-order knowledge and comprehension of group characteristics. Since students have difficulties learning evolution (Alters and Nelson 2002, Hokayem and Boujaoude 2008) and extensive hands-on observations of products of evolution (i.e. biodiversity) provide a powerful opportunity for students to learn about evolution in a meaningful way, we contend that these hands-on labs can be designed in such a way that students can improve their grasp of lower-order declarative knowledge in addition to their evolution-based higher-order integration of concepts and science-based reasoning. We proposed that a reduction in overall content and additional time with engaging hands-on activities focused on lower-order, foundational information could set the scene for students to improve their understanding
Table 5 t-test results from comparison of lecture exam performance based on enrollment in lab

\begin{tabular}{lllll}
\hline & \multicolumn{3}{l}{ Unpaired t-test results } & Difference $(95 \% \mathbf{C l})$ \\
\hline Blooms-level & $t$ & $d f$ & $p$ & \\
(a) Pre-assessment & & & & \\
Know/comp & -0.21 & 590 & 0.83 & - \\
Application & 0.072 & 593 & 0.94 & - \\
Analysis & -0.62 & 587 & 0.53 & - \\
(b) Exam: unrelated & 3.48 & 909.9 & $<0.001$ & $4.32(1.9-6.8)$ \\
(c) Exam: lab \& lecture & & & & \\
Knowledge & 9.76 & 973.6 & $<0.001$ & $11(8.8-13)$ \\
Comprehension & 7.21 & 949.7 & $<0.001$ & $9.0(6.6-11)$ \\
Application & 7.36 & 968.4 & $<0.001$ & $8.9(6.5-11)$ \\
Analysis & 6.32 & 952.9 & $<0.001$ & $6.3(3.6-9.0)$ \\
(d) Difference & 4.3 & 959.0 & $<0.001$ & $5.9(3.2-8.6)$ \\
\hline
\end{tabular}

Scores were compared for lecture + lab and lecture-only students for (a) Pre-Assessment, (b) Exam material that was not covered in lab (Exam: Unrelated). (c) Exam material that was covered in both lab and lecture (Exam: Lab \& Lecture), (d) the difference in exam performance on questions covered in both lab and lecture and questions unrelated-to-lab for each individual student (Difference).

of evolution-based higher-order integration of concepts and evidence-based science reasoning. In the model, we incorporated pre-lab learning activities to engage students and give them hands-on opportunities to learn foundational lower-order terminology/concepts and to help provide a framework for the higher-order integrative learning. We reduced the phyla/divisions examined by students from 6 to 4 to focus students on the higher-order learning goals: emphasis on evolution-based higher-order integration of concepts and evidence-based science reasoning in the post-lab write up. Results of this study support our contention.

\section{Comparisons of students in this study are valid and} assessment categorizations into Bloom's levels are reliable The validation by two independent reviewers of categorization of assessment questions as knowledge, comprehension, application, and analysis by JMB indicated high reliability (Table 4).

The clicker-based content pre-assessment results indicated that our comparison groups (students in lecture + lab vs. lecture only) were not significantly different with respect to course content, and performed similarly on higher and lower-order cognition items (Figure 1), indicating that

Table 4 Reliability estimates for the categorization of pre-exam and exam questions $(N=42)$ into Bloom's levels of learning by two independent reviewers compared with categorizations of assessments used in the analysis

\begin{tabular}{lllllll}
\hline Independent reviewer & $\boldsymbol{K}_{\text {qw }}$ & $\mathrm{SE}$ & Lower $\mathbf{9 5 \%} \mathrm{Cl}$ & Upper 95\% Cl & $\boldsymbol{K}_{\text {qwmax }}$ & Adjusted $\boldsymbol{K}_{\text {qw }}$ \\
\hline 1 & 0.863 & 0.035 & 0.793 & 0.932 & 0.954 & 0.904 \\
2 & 0.870 & 0.006 & 0.861 & 0.884 & 0.931 & 0.937 \\
\hline
\end{tabular}

$K_{q w}=$ quadratic weighted kappa, $S E=$ standard error, $\mathrm{Cl}=95 \%$ confidence interval, $K_{\text {qwmax }}=$ the maximum quadratic weighted kappa for the observed marginal frequencies, and Adjusted $K_{q w}=$ the observed proportion of the $K_{\text {qwmax }}$ (Cohen 1968, Sim and Wright 2005). 


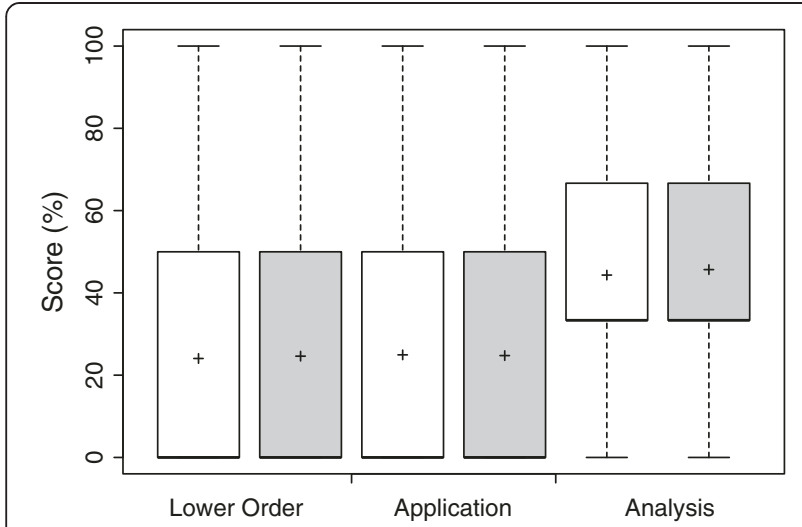

Figure 1 Pre-assessment scores (\%) of students in lab + lecture and lecture only. Scores (\%) on pre-assessment by Bloom's level. Box color indicates students concurrently in lab and lecture (light boxes, $n=399$ ) or in lecture only (dark boxes, $n=201$ ). Boxes connect upper and lower quartile. The bars are medians, pluses indicate mean values, whiskers indicate range of values, and open circles are outliers.

our subsequent comparisons of lecture + lab to lecture only student performance is valid. Although the pre-assessment was administered in 2013, we reasoned that student motives for taking lecture with or without lab should have been the same in 2011 as they were in 2013. Furthermore, in both 2011 and 2013, the instructors who began the class were the same and the class times were the same. Since the pre-test was given in advance of instruction, we reason that instructional differences between 2011 and 2013 were also negligible. Thus, with a large enough sample size to achieve similar distributions ( $>600$ in this case), a pre-test comparing students in lecture + lab to students in lecture only in 2013 should have been representative for the situation in 2011.

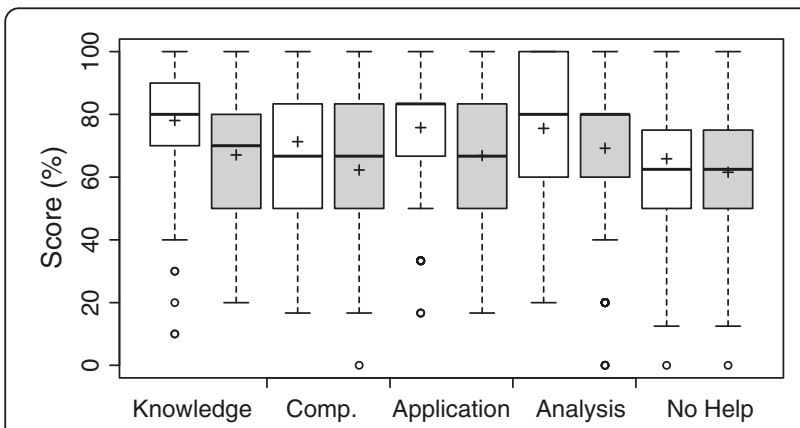

Figure 2 Post assessment scores (\%) of students in lab + lecture and lecture only. Scores on exam categorized by Bloom's level. Material was related to lab for analyses except for "Unrelated". Box color indicates students in lab + lecture (light boxes, $n=421$ ) or in lecture only (dark boxes, $n=558$ ). Boxes connect upper and lower quartile. The bars are medians, pluses indicate mean values, whiskers indicate range of values, and open circles are outliers.
This study utilized a quasi-experimental design with a nonequivalent control group. Since the control group was comprised of students in lecture without lab, and in the lab students allocated up to 3.5 hours per week of study, we could not draw conclusions about how learning associated with this lab design compared to other forms of instruction occupying equivalent time. For example, if students had a supervised study experience that required approximately 3 to 3.5 hours a week beyond the lecture, we are unable from this study to compare the lab experience to that of the theoretical supervised study experience. However, since the two comparison groups were assessed as equivalent at the start of the semester, by comparing students in lecture + lab to students in lecture alone with post-lab assessment questions related and unrelated to the lab, we could draw conclusions concerning whether or not the biodiversity lab combined with the inquiry-oriented lab curriculum improved student understanding of scientific evidence and reasoning associated with evolution.

\section{Revised plant biodiversity labs met targeted learning goals} Student performance on exam questions that pertained to the learning goals outlined in Table 2 indicated that at each of Bloom's levels examined, students in lab and lecture significantly outperformed students in lecture only. On average, students in lecture + lab performed approximately $10 \%$ better on lower-order cognition items

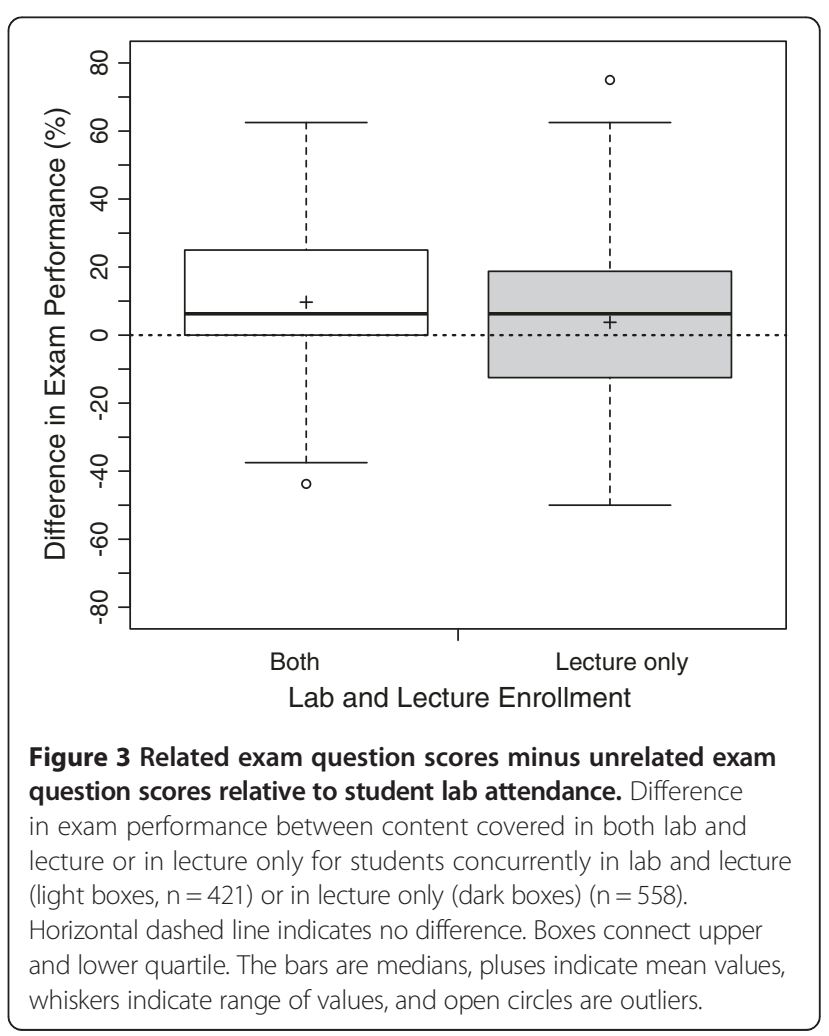


and approximately $7.6 \%$ better on higher-order evolutionbased integration of concepts and evidence-based reasoning items (Table 5). One potential problem with this assessment was that we did not utilize previously verified questions in the construct of the assessment and the questions used on the assessment were not randomly selected from a large group of questions. However, to avoid experimental bias, 10 questions were written at each level of learning examined and the lecture professor who did not have specific knowledge of the lab chose 5 of the 10 questions that all had direct relevance to lecture material. In addition, questions on the exam written by the professor that pertained to plant biodiversity were analyzed as well, and these questions also showed the same pattern in student performance. With this construct, a lack of a significant difference between treatments could arguably be because of the exam items chosen, but a significant difference most likely reflects differences in learning at multiple levels between the two groups of students.

\section{Inquiry-oriented lab experience may improve evolution-based learning}

Results of this study also imply that the overall inquiryoriented lab experiences somehow helped students in lecture beyond just direct transfer/facilitation of content understanding. On lower-order questions unrelated to the lab, students in lab + lecture outperformed students in lecture alone by $4.32 \%$. When we subtracted the unrelated lower-order exam questions from the related ones, students in lab + lecture outperformed students in lecture alone beyond the unrelated questions by $5.9 \%$. Since we did not have any higher-order unrelated exam questions for comparison, we were unable to estimate the proportion that the plant-biodiversity lab itself versus the other inquiry-oriented experiences improved higher-order learning. These results are not surprising because research shows that inquiry instruction improves reasoning abilities over didactic instruction in college introductory biology classes (Lawson and Johnson 2002, Jensen and Lawson 2011). Johnson and Lawson (1998) found that reasoning ability in a college introductory biology class was a better predictor of student success on the comprehensive final exam than prior knowledge or prior biology classes, and that their inquiry-based treatment improved reasoning over their expository treatment. These results indicate that a practical framework for attaining evolution-based higher-order integration and science reasoning in biodiversity labs would not only include a reduction in content and an increase in time, but also other inquiry-oriented lab experiences.

\section{Conclusions}

Results of this study indicate that a plant biodiversity lab with extended hands-on exposure to lower-order foundational content, a reduction in the number of plant groups examined, a written post-lab experience emphasizing higher-order cognition, and multiple inquiry experiences in lab can improve conceptual understanding of evolution and evidence-based science reasoning. This research supports the contention that "march through the phyla" biodiversity labs can be successfully reconfigured to improve student understanding of evolution.

\section{Abbreviation}

GBLII: Second semester general biology lab.

\section{Competing interests}

The authors declare that they have no competing interests.

\section{Authors' contributions}

This research project was a smaller component of a larger research project. $J M B$ was responsible for designing the research, supervising various aspects of the research and writing the manuscript. APM and CDF were substantially involved with the total project including data collection, analysis and presentation, in addition to providing comments on the manuscript. BM, SBW, RJS and PTJ were involved with assessment writing and implementation as well as providing comments on the manuscript. All authors read and approved the final manuscript.

\section{Acknowledgements}

We thank 4 anonymous reviewers for insightful comments on the manuscript. Funding was provided by the Integrating STEM (iSTEM) Education Initiative. CDF was supported by the University of Colorado Graduate School and the National Evolutionary Synthesis Center (NESCent; NSF \#EF-0905606). Funding agencies were not involved with specifics associated with the research or manuscript preparation.

\section{Author details}

${ }^{1}$ Department of Ecology and Evolutionary Biology, University of Colorado at Boulder, 334 UCB, Boulder, CO 80309-0334, USA. ${ }^{2}$ NESCent: the National Evolutionary Synthesis Center, 2024W. Main St., Suite A200, Durham, NC 27705, USA

Received: 7 August 2013 Accepted: 17 March 2014

Published online: 01 April 2014

\section{References}

Addy, HD, \& Longair, RW. (2009). Laboratory manual for biology 223, organismal biology of plants and animals. Plymouth, Ml: Hayden McNeil Publishing Inc.

Alters, BJ, \& Nelson, CE. (2002). Perspective: teaching evolution in higher education. Evolution, 56, 1891-901.

American Association for the Advancement of Science. (2010). Vision and change in undergraduate biology education: A call to action. DC: Washington.

Cohen, J. (1968). Weighted Kappa: nominal scale agreement with provision for scaled disagreement or partial credit. Psychological Bulletin, 70, 213-220.

Crowe, A, Dirks, C, \& Wenderoth, MP. (2008). Biology in bloom; implementing Bloom's taxonomy to enhance student learning in biology. CBE Life Science Education, 7, 368-381.

Harris-Haller, T. (2008). Laboratory manual for biology 112 (4th ed.). Plymouth, Ml: Hayden McNeil Publishing Inc.

Heil, CSS, Hunter, MJ, Noor, JKF, Miglia, K, Manzano-Winkler, B, McDermott, SR, \& Noor, MAF. (2012). Witnessing phenotypic and molecular evolution in the fruit fly. Evolution Education Outreach, 5, 629-634.

Hokayem, H, \& BouJaoude, S. (2008). College students' perceptions of the theory of evolution. Journal of Research in Science Teaching, 45, 395-419.

Jensen, L, \& Lawson, AE. (2011). Effects of collaborative group composition and inquiry instruction on reasoning gains and achievement in undergraduate biology. CBE-Life Sciences Education, 10, 64-73.

Johnson, MA, \& Lawson, AE. (1998). What are the relative effects of reasoning ability and prior knowledge on biology achievement in expository and inquiry classes? Journal of Research in Science Teaching, 35(1), 89-103. 
Kalinowski, ST, Taper, ML, \& Metz', AM. (2006). Can random mutation mimic design?: a guided inquiry lab for undergraduate students. Genetics, 174, 1073-1079.

Lawson, AE, Abraham, MR, \& Renner, JW. (1989). A theory of instruction: Using the learning cycle to teach science concepts and thinking skills. NARST Monograph, Number One. Cincinnati, Ohio: National Association for Research in Science Teaching.

Lawson, AE, Clark, B, Cramer-Meldrum, E, Falconer, KA, Sequist, JM, \& Kwon, YJ. (2000). Development of scientific reasoning in college biology: Do two levels of general hypothesis-testing skills exist? Journal of Research in Science Teaching, 37, 81-101.

Lawson, AE, \& Johnson, M. (2002). The validity of Kolb learning styles and neo-Piagetian developmental levels in college biology. Studies in Higher Education, 27(1), 79-90.

Meisel, RP. (2010). Teaching tree-thinking to undergraduate biology students. Evolution (NY), 3(4), 621-628.

Miller, GD. (1956). The magical number seven plus or minus two: some limits on our capacity for processing information. Psychology Review, 63, 81-97.

National Research Council. (1998). Teaching About Evolution and the Nature of Science. Washington, DC: National Academies Press.

$R$ Core Team. (2012). R: A language and environment for statistical computing. Vienna, Austria: R Foundation for Statistical Computing. www.r-project.org.

Reid, N. (2008). A scientific approach to the teaching of chemistry. What do we know about how students learn in the sciences, and how can we make our teaching match this to maximize performance? Chemistry Education Research and Practice, 9, 51-59.

Scully, TA, \& Fisher, RWW. (2009). Discovering biology in the lab, an introductory laboratory manual. New York, NY: Norton \& Company.

Sim, J, \& Wright, CC. (2005). The kappa statistic in reliability studies: use, interpretation, and sample size requirements. Physical Therapy, 85(3), 257-268.

Spiro, MD, \& Knisely, KI. (2008). Alternation of generations and experimental design: a guied-inquiry lab exploring the nature of her1 developmental mutant of Ceratopteris richardii (C-fern). CBE-Life Science Education, 7, 82-88.

Smith, JJ, \& Cheruvelil, S. (2009). Using inquiry and tree-thinking to "March through the animal phyla": teaching introductory comparative biology in an evolutionary context. Evolution Education Outreach. doi:10.1007/s12052-009-0156-x.

Timmerman, BE, Strickland, DC, \& Carstensen, SM. (2008). Curricular reform and inquiry teaching in biology: where are our efforts most fruitfully invested. Integrative and Comparative Biology, 48(2), 226-240.

van Merrienboer, JJG, \& Sweller, J. (2005). Cognitive load theory and complex learning: recent developments and future direction. Educational Psychology Review, 17, 147-177.

Vodopich, D, \& Moore, R. (2008). Biology, laboratory manual to accompany Brooker Biology. New York, NY: McGraw-Hill.

doi:10.1186/s12052-014-0010-7

Cite this article as: Basey et al: Impact of pre-lab learning activities, a post-lab written report, and content reduction on evolution-based learning in an undergraduate plant biodiversity lab. Evolution: Education and Outreach 2014 7:10.

\section{Submit your manuscript to a SpringerOpen ${ }^{\circ}$ journal and benefit from:}

- Convenient online submission

- Rigorous peer review

- Immediate publication on acceptance

- Open access: articles freely available online

- High visibility within the field

- Retaining the copyright to your article

Submit your next manuscript at $\gg$ springeropen.com 